\title{
EFEITOS COLATERAIS E DESACERTOS NA TERAPEUTICA ANTIEPILETICA
}

\author{
Eneida Baptistete Matarazzo * \\ JoRGE MATSUMOTO **
}

Diante do enorme progresso alcançado nas últimas décadas no tratamento medicamentoso das doenças neurológicas e psiquiátricas, pode-se afirmar que a terapêutica da epilepsia é das que menos evoluiram.

Se incluirmos nessa entidade nosográfica, não apenas as crises, mas também a imensa gama de sintomas físicos e psíquicos não-ictais como cefaléia ${ }^{1}$, tontura $^{1}$, medo ${ }^{1}$, agressividade ${ }^{5}$, e outros, causados pela disritmia cerebral, que é o substrato neurofisiológico da epilepsia, podemos afirmar que uma porcentagem bastante significativa da população (talvez $10 \%$ ou mais) pode beneficiar-se desse tipo de tratamento.

Surpreende, por isto, que as pesquisas no sentido de encontrar novas drogas antiepiléticas não sejam mais intensas. Um dos mais eficazes, entre esses produtos, continua sendo o fenobarbital, usado como anticonvulsivante desde 1912. Desde então, poucos entre os medicamentos propostos resistiram às restrições da classe médica e demonstraram real eficácia como antidisritmicos. Os mais usados atualmente em nosso meio são o fenobarbital, a difenil-hidantoina, o prominal, a primidona, a fenurona, a tridione e, de lançamento comercial mais recente, a carbamazepina e os derivados benzo-diazepínicos (diazepan, nitrazepan e clonazepan). Entretanto, nenhum dos medicamentos citados pode ser considerado eficaz em todos os casos de disritmia cerebral e nenhum deles é isento de inconvenientes, podendo produzir eventuais efeitos colaterais.

Este fato torna a epilepsia, a nosso ver, uma das doenças mais dificeis de serem tratadas e das que maiores cuidados exigem no seguimento.

O presente trabalho pretende ser uma contribuição no sentido de lembrar, ao especialista, que é necessário estar sempre atento aos efeitos colaterais quando se prescreve tratamento antiepilético e, ao mesmo tempo, demonstrar, pela casuística apresentada, que é possível evitá-los, sem prejuízo do controle dos sintomas comiciais.

* Prof. Assistente do Departamento de Neuro-Psiquiatria da FMUSP na Disciplina de Psiquiatria Infantil; ** Médico-adido do Serviço de Psiquitria Infantil do Hospital das Clínicas da FMUSP. 


\section{CASUISTICA}

Os seis pacientes cuja evoluçāo é estudada neste trabalho foram atendidos no Ambulatório do Serviço de Psiquiatria Infantil. Alguns deles foram encaminhados por outros Serviços do Hospital das Clínicas ou particulares, onde haviam sido feitos exames para-clínicos para elucidação diagnóstica, que por isso não foram repetidos durante o tratamento conosco. Foram realizados exames de liquido cefalorraqueano (LCR), eletrencefalograma (EEG) e radiografias do crânio quando se mostraram necessários para esclarecimento do diagnóstico. Três desses pacientes, devido à gravidade da sintomatologia e à dificuldade de seguimento estiveram internados durante um certo periodo, continuando depois o tratamento no Ambulatório. Todas as doses referidas nas observaçoes são diárias e por via oral.

CASo 1 - P. R. H. (Reg. 56740), 13 anos, sexo masculino, amarelo, brasileiro. O paciente nasceu cego e prematuramente, tendo permanecido em encubadeira nos 3 primeiros meses de vida. Teve retardo de desenvolvimento psico-motor, andando e falando em torno dos 4 anos. Desde os primeiros anos de vida mostrou-se irritadico, impulsivo, agressivo e revelou acentuada dificuldade de aprendizado. Aos 8 anos foi colocado em escola para cegos, mas teve problemas de adaptação: queixava-se sobretudo de nāo suportar o barulho das vozes dos colegas, o que o deixava muito irritado. Aos 10 anos começou a apresentar crises de "ausência temporal", com duração de aproximadamente 1 minuto, seguidas de torpor e sonolência. Foi medicado com associação de fenobarbital $50 \mathrm{mg}$, prominal $50 \mathrm{mg}$ e difenil-hidantoina $50 \mathrm{mg}$ (Comital L); tornou-se mais agressivo desde então e foi associada butirofenona (Haloperidol), 5 gotas ao dia, para acalmá-lo. Apesar do tratamento, as "ausências", que no início surgiam cada 2 meses, foram-se tornando mais freqüentes; um ano depois começou a apresentar também crises tipo GM. Por outro lado, o comportamento foi-se agravando progressivamente; mostrava-se permanentemente agressivo, agitado, tinha freqüentes crises de cólera e a intolerância aos ruídos aumentou; automutilava-se nos momentos de maior irritação. Em fevereiro de 1974 foi examinado na Clínica Neurológica do HC, tendo feito EEG e LCR, ambos com resultado normal. Devido aos distúrbios de conduta foi encaminhado ao nosso serviço.

Em abril de 1974 iniciamos o tratamento, substituindo toda a medicacão anterior por carbomazepina (Tegretol), 2 comp. de $200 \mathrm{mg}$ ao dia. Houve melhora rápida na conduta do paciente. Após alguns dias já se mostrava mais calmo e acessivel, tendo momentos de irritaçāo passageira; também não manifestava tanta intolerância a ruídos. Como a melhora estabilizou, em agosto de 1974 foi medicado com fenobarbital (Gardenal), $100 \mathrm{mg}$, e carbamazepina, $200 \mathrm{mg}$. Com esse tratamento, até março de 1975 , o paciente permanecia calmo, tolerando bem os ruídos e sem manifestações comiciais.

CASo 2 - M. A. R. (Reg. 55712), sexo feminino, branca, 10 anos. A paciente nasceu de parto normal e até os 6 anos era uma criança sadia, com desenvolvimento psico-motor correspondente à idade e comportamento adequado. Aos 6 anos, durante quadro febril, teve crise generalizada tônico-clônica; devido a esta ocorrência foi feito eletrencefalograma que evidenciou "atividade convulsigena bi-temporal, de provável localização profunda". Desde então foi medicada por neurologista, com associação de fenobarbital $(50 \mathrm{mg})$, difenil-hidantoina $(50 \mathrm{mg})$ e prominal $(50 \mathrm{mg})$. Passou bem até os 8 anos. Nessa idade a paciente. que era tranquila e corajosa, começou a mostrar medo de numerosas situações como, por exemplo, escuro, sair só, ser raptada, ver pessoas mortas ou cemitérios, ficar doente; de forma geral preocupava-se com tudo que representava risco de morte para si e para os pais. Em setembro de 1973 (tinha 9 anos e 6 meses) apresentou hipertrofia gengival, que foi relacionada ao uso da difenil-hidantoina. A dose dos remédios foi reduzida pela metade e como surgiu intensa cefaléia, foram substituidos por primidona (Mysoline), na dose diária de $500 \mathrm{mg}$. Após alguns dias seu comportamento agravou-se e surgiram distúrbios físicos, como diarréia e dor epigástrica sem causa digestiva aparente. Em novembro seu medo era tão intenso que se recusava a ficar sozinha, qualquer 
que fosse a circunstância. Com três meses de uso da primidona começou a manifestar sensação de estranheza em relação a pessoas. Julgaıa que seu pai não era o mesmo, embora fosse fisicamente parecido; "é como se fosse o gêmeo dele", dizia. Dias depois começou a estranhar os lugares, os demais familiares e achava que ela própria já não era a mesma pessoa. Tornou-se desconfiada, procurava ouvir as conversas dos pais, achando que deviam estar falando a respeito de sua morte.

Foi levada a um psiquiatra que, atribuindo os distúrbios a causas emocionais acrescentou à medicação 15 gotas, ao dia, de butirofenona e $100 \mathrm{mg}$ de nialamida (Niamid) por via oral. Alguns dias depois, além da persistência dos distúrbios anteriores, a paciente manifestou depressão, tinha crises frequientes de choro imotivado e sintomas de tipo obsessivo-compulsivo (por exemplo, media os objetos com a palma da mão, angustiava-se se o dedo minimo não coincidia com o final daqueles e repetia o ato até que a coincidência ocorresse). Devido à sua doença, deixou de freqüentar a escola, pois não conseguia mais estudar.

Foi examinada por outro psiquiatra, que após narcoanálise considerou seus sintomas decorrentes de conflitos familiares e a encaminhou para fazer psicanálise. Não aceitando a conclusão acima, seus pais a trouxeram ao Ambulatório do Serviço de Psiquiatria Infantil, em 16 de janeiro de 1974. Nesta ocasião a paciente se apresentava deprimida, angustiada, muito atemorizada e referia sensação permanente de estranheza em relação a si própria e ao mundo circundante, parecendo perplexa ante este fato que não conseguia explicar. Revelava percepção visual e auditiva correta, evidenciando que o julgamento da realidade é que se achava perturbado. Mostrava-se lentificada, elaborando com dificuldade as respostas. Referia medo constante e difuso e descrevia impulsos de tipo obsessivo-compulsivo que geravam angústia se não realizados. Essas manifestações indicavam uma psicose incipiente, provavelmente iatrogênica, por ação tóxica de primidona. Iniciamos redução progressiva desta última (50 $\mathrm{mg}$ cada 3 dias), substituindo-a por carbamazepina (100 mg cada 3 dias, até o total de $400 \mathrm{mg}$ ). Houve melhora rápida e progressiva de todos os sintomas. Revimos a menor após 15 dias e já então se mostrava alegre, raciocinava com facilidade, referia diminuição do medo patológico e tinha raros momentos de estranheza.

Quatro meses depois a paciente estava bem, psiquicamente, sendo sua única queixa, a de persistência do medo, embora bastante atenuado. Devido a esse último reduzimos a carbamazepina (4C0 $\mathrm{mg}$ para $200 \mathrm{mg}$ ) e acrescentamos fenobarbital (50 mg). Em poucos dias desapareceram as manifestações de medo.

Até abril de 1975 a paciente continuava com o tratamento acima e não apresentava qualquer alteração da esfera psiquica, nem queixas somáticas. Tinha ótima disposição, mostrava-se bem humorada e freqüentava o 4." ano primário com excelente aproveitamento.

Caso 3 - D. A. F. (Reg. 55935), sexo feminino, branca, 13 anos. A paciente nasceu bem e teve condições normais de desenvolvimento psico-motor. Até os 11 anos era calma e bem comportada. Nessa época comecou a apresentar crises convulsivas tipo GM. Examinada na Clínica Neurológica do Hospital das Clinicas, foi medicada com associação diária, por via oral, de prominal (50 mg), difenil-hidantoina (50 mg) e fenobarbital $(50 \mathrm{mg})$. As crises não se repetiram, porém a paciente começou a apresentar freqüentes abalos musculares e piloereção. Foi duplicada a dose dos medicamentos e como nāo melhorasse acrescentaram-se $200 \mathrm{mg}$ de difenil-hidantona, diariamente. Desde esse último aumento a paciente tornou-se muito irritada, agressiva, impulsiva e mal-humorada. Cerca de 3 meses depois, após discussão com um parente, tentou suicidio, ingerindo grande quantidade dos medicamentos que vinha tomando. Entrou em coma profundo, foi hospitalizada e 5 dias após teve alta, com total recuperação. Continuou sendo medicada com o mesmo esquema terapêutico. Poucos dias depois começou a apresentar crises tipo GM, mioclonias e crises de automatismo temporal: queixava-se de cefaléia e tontura e continuava com os graves distúrbios de conduta e do humor acima citados. Devido a esses últimos e á tentativa de suicidio foi encaminhada ao Ambulatório de Psiquiatria Infantil. 
o exame psíquico, nessa ocasião, nāo revelou outros distúrbios além da irritabilidade e da tendência a responder às frustrações de forma auto e hétero-agressiva e impulsiva. Não evidenciava desejo consciente de morrer, parecendo a tentativa de suicidio um claro ato de impulsividade epilética. Admitindo que os distúrbios poderiam estar relacionados ao tratamento antiepilético (prominal $100 \mathrm{mg}$; fenobarbital $100 \mathrm{mg}$; difenil-hidantoina $300 \mathrm{mg}$ ), modificamos sucessivamente as prescrições, dentro do seguinte esquema: em 31-10-73, fenobarbital (100 mg), prominal (50 $\mathrm{mg}$ ) e difenil-hidantoina $(50 \mathrm{mg})$; em 16-11-73, fenobarbital (200 mg); em 01-02-74, fenobarbital (100 mg) e carbamazepina (200 mg); em 24-05-74, fenobarbital (100 mg) e carbamazepina $(400 \mathrm{mg})$. Desde o início, com redução de doses em relação ao tratamento anterior, houve melhora do quadro clínico; a paciente mostrava-se menos irritada e as crises se espacaram. Com a suspensão da difenil-hidantoina nāo teve mais crises; o humor melhorou sensivelmente com a introdução de carbamazepina. Até outubro de 1974, com a última medicação, a paciente mantinha bom equilibrio emocional: mostrava-se calma, alegre e não tinha quaisquer manifestações ictais. Sua única queixa era diminuição na memória de fixação.

CASO 4 - M. B. L. M. (Reg. 54349), sexo masculino, branco, 16 anos. O paciente nasceu bem e teve desenvolvimento psico-motor normal até a idade de 2 anos. Nessa ocasião apresentou crise convulsiva tipo GM; alguns meses depois teve nova crise e passou a ser medicado com associação, por via oral e diariamente, de prominal (50 $\mathrm{mg}$ ), difenil-hidantoina $(50 \mathrm{mg}$ ) e fenobarbital $(50 \mathrm{mg})$, além de primidona (250 $\mathrm{mg}$ ). Manteve esse tratamento até os 12 anos e não teve mais crises. Nesse periodo foram feitos alguns eletrencefalogramas, com resultado anormal. O paciente mantinha-se bem humorado, era afetuoso e obediente, porém desde o inicio das manifestaçôes epiléticas revelou dificuldade de aprendizado, com retardo acentuado no desenvolvimento psico-motor. Aos 12 anos de idade começou a apresentar episódios de excitação e de agitação psico-motora: tornava-se agressivo, instável, irritado, ria sem motivo aparente, insultava as pessoas, masturbava-se em público, comia exageradamente, desconhecia os familiares, falava continuadamente, perdia-se na rua quando conseguia fugir de casa. Esses episódios duravam horas, dias e até semanas; o mais demorado foi de 6 meses. Nos intervalos, que tinham duração de dias, comportava-se como antes.

Devido a essas manifestações foram feitas várias tentativas terapêuticas, substituindo-se a medicação anterior. Foi prescrito carbamazepina, que provocou reação alérgica (erupção morbiliforme generalizada). Foram feitas várias associações com propericiazina (Neuleptil), ácido gama-amino-butírico (Gammar), prednisona (Meticorten), difenil-hidantoina, fenobarbital, diazepan, butirofenona, ospolot e outros. Nenhum dos tratamentos alterou o curso da doença. O paciente foi hospitalizado e fez tratamento por eletro-choque, sem resultado.

Devido aos distúrbios psíquicos foi traduzido ao Ambulatório da Psiquiatria Infantil, em julho de 1973. Na ocasião da consulta mostrava-se levemente torporoso, desorientado, com atenção dispersiva e memória de fixacão quase nula; raciocinava lentamente, e demonstrava acentuado déficit de abstração; viscoso, repetia inúmeras vezes a mesma pergunta, após ter sido respondida; tinha risos imotivados, mostrava déficit de crítica; tinha excitação sexual quase permanente e masturbava-se diante do examinador; mantinha, porém, satisfatório relacionamento afetivo com os familiares. Internado para melhor observação, o paciente permaneceu alguns dias. sem medicação e com os disturbios citados acima; mostrava-se totalmente apragmático e desinteressado do contato social.

Embora os distúrbios psiquicos pudessem indicar uma psicose epilética, a seqüência com que vinham ocorrendo e a duração tão variável fizeram-nos admitir, como diagnóstico provável, crises psico motoras e episódios confusionais correspondentes a sintomas epiléticos propriamente ditos e que deveriam, então, ser tratados com drogas anti-comiciais e não com neuroléticos em altas doses, como seria o indicado se fosse psicose epilética. Foi prescrito primidona (750 $\mathrm{mg}$ ao dia) e como não melhorasse foi medicado com fenobarbital (100 mg). O comportamento tornou-se mais adequado, porém permanecia sonolento e a dose foi reduzida para $50 \mathrm{mg}$ 
diários. Progressiva e lentamente foi melhorando; desapareceram os distúrbios da linha psicótica, a viscosidade diminuiu muito, passou a ter bom convivio social. A atencão, entretanto, continuava dispersiva e por isso não aproveitava os ensinamentos na Terapia Ocupacional; foi acrescentado ácido glutâmico à medicação, com bons resultados sobre a memória e a atenção.

Desde maio de 1974, vem sendo medicado com $50 \mathrm{mg}$ de fenobarbital e $150 \mathrm{mg}$ de ácido glutâmico. Até fevereiro de 1975 não voltou a ter períodos de agitação, nem outros sintomas ictais. Mostrava-se em geral de ótimo humor, afetuoso com seus familiares, obediente. Sua memória de fixação melhorou sensivelmente e o pragmatismo idem. Frequientava o Centro de Treinamento da Associação de Pais e Amigos de Excepcionais e, pela primeira vez, em toda sua vida, mostrava-se capaz de realizar bem uma tarefa útil e ordenada. Aprendia um oficio e falava com entusiasmo na possibilidade de obter logo um emprego remunerado. Sua família afirmava que durante todos os anos em que foi tratado, só agora tinha comportamento realmente adequado, além de revelar capacidade de prendizado sensivelmente melhor.

CASO 5 - R. J. S. (Reg. 55327), sexo feminino, branca, 15 anos. A paciente nasceu cianótica, após parto prolongado, demorando a chorar. No 2.0 dia de vida teve várias crises convulsivas tipo GM. Foi medicada com associaça de prominal (50 $\mathrm{mg}$ ), difenil-hidantoina $(50 \mathrm{mg}$ ) e fenobarbital $(50 \mathrm{mg})$, mantendo essa terapêutica até os 8 anos, apesar de ter algumas crises convulsivas anualmente e de manifestar problemas de conduta. Aos 2 anos sofreu contusão craniana, seguida de perda de consciência de alguns minutos; nessa ocasião já andava e falava e o acidente não afetou o desenvolvimento psico-motor. Desde 1 ano, mostrava-se irritadiça, agressiva, impulsiva e colérica. Embora parecesse ter nível mental normal (comparada com outras crianças), ao iniciar a escola revelou certa dificuldade de aprendizado, repetindo o $1^{\circ}$, o $2^{\circ}$ e o $3^{\circ}$ anos. Devido ao seu comportamento agressivo, aos 8 anos foi acrescentada, à medicação anterior, butirofenona (0,4 mg ao dia), ficando um pouco mais calma e sem crises.

Aos 13 anos passou a ser tratada na Clinica Neurológica do Hospital das Clinicas. Foi medicada com fenobarbital (100 $\mathrm{mg})$ e difenil-hidantoina (200 $\mathrm{mg})$. Passou bem alguns meses, mas depois os distúrbios de conduta se reativaram, tornando-se extremamente agressiva e irritadiça. Em novembro de 1973 comecou a revelar acentuada dificuldade de aprendizado (fazia o $4 .^{\circ}$ ano primário) e informava que tinha visão dupla dos objetos. Devido à conduta foi encaminhada ao Ambulatório de Psiquiatria Infantil, em novembro de 1973. Na ocasião da consulta, além de diplopia e tremores finos generalizados, verificados no exame clínico, mostrava-se torporosa, apática, com lentificação de raciocínio, diminuição na memória de fixação e de evocação e embotamento afetivo; referia irritabilidade fácil e tendência a reagir explosivamente quando contrariaua.

Admitindo que apresentava quadro iatrogênico, provavelmente por ação tóxica da difenil-hidantoina, suspendemos esse medicamento em 28-11-73, introduzindo carbamazepina (200 mg) e mantendo $100 \mathrm{mg}$ de fenobarbital. Uma semana após haviam desaparecido a diplopia e o torpor e a paciente dizia estar mais calma. Como teve crise convulsiva alguns dias depois, foi aumentada a carbamazepina para 400 mg. Houve melhora na escolaridade também, mas como se queixava de dificuldades em memorizar as lições foi prescrito ácido glutâmico (150 mg ao dia). Com esse tratamento, de dezembro de 1973 até março de 1975 a paciente não teve quaisquer manifestações ictais, mostrava-se calma, com bom controle emocional e ótimo. aproveitamento escolar (4.0 ano primário).

CASO 6 - F. R. T. (Reg. 56656), sexo masculino, branco, 3 anos. O paciente nasceu bem e teve desenvolvimento psico-motor correspondente à idade. Aos 2 anos comecou a apresentar crises convulsivas tipo GM e outras de perda de tonus e queda, sem perda de consciência. Foi medicado por neurologista, inicialmente, com fenobarbital (15 mg) e como as crises continuassem, as doses foram progressivamente aumentadas até $200 \mathrm{mg}$ ao dia. A partir de $50 \mathrm{mg}$, o paciente, que era 
alegre e loquaz, tornou-se instável, agressivo e irritadiço e falava muito pouco. Com $200 \mathrm{mg}$ tornou-se sonolento, apático e prostrado e teve crises mais frequientes. Devido a esse estado, foi trazido ao Ambulatório de Psiquiatria Infantil, em junho de 1974. O EEG feito na ocasião não revelou anormalidade. O paciente foi medicado com fenobarbital (100 mg) e difenil-hidantoina (100 mg). Como não melhorava, foi internado para melhor observação.

Em julho de 1974 foi suspenso o fenobarbital e aumentada progressivamente a dose de difenil-hidantoina ate $300 \mathrm{mg}$ ao dia. O paciente deixou de ter crises tipo GM, porém surgiram mioclonias e crises de ausência fugazes, que sugeriram o diagnóstico de síndrome de Lennox, não confirmado, entretanto pelo traçado eletrencefalográfico. No 10." dia de tratamento pela difenil-hidantoina comecou a apresentar vômitos freqüentes, não controláveis pela medicação anti-emética. Como nāo verbalizava suas queixas, o diagnóstico etiológico tornou-se difícilí mas admitimos a hipótese de uma gastrite aguda pela difenil-hidantoina que foi substituída pela carbamazepina (400 mg). Os vômitos se reduziram, desaparecendo no 3." dia, mas o paciente continuou com ausēncias e mioclonias tão freqüentes que precisava ser mantido em cadeira de rodas para năo se ferir nas quedas. Novo EEG revelou espiculas-ondas lentas difusas, de freqüência variável (geralmente $2 \mathrm{c} / \mathrm{s}$ ), confirmando que se tratava de sindrome de Lennox. Foi medicado com nitrazepan (200 mg) e as crises mioclônicas desapareceram; apesar de ligeiramente sonolento, mostrava-se alegre, brincava e corria pela enfermaria. Após 12 dias, entretanto, reapareceram as crises tipo GM. Foram necessárias várias tentativas de associação de cirogas para chegar-se a um esquema terapêutico satisfatório. Com doses diárias de nitrazepan (250 $\mathrm{mg}$ ) e carbamazepina (400 mg) desapareceram as ausências e as mioclonias. Até abril de 1975 manifestavam-se apenas crises raras, leves e de curta duração de perda de consciência, com ou sem convulsão. Do ponto de vista psiquico notava-se uma conduta perfeitamente compativel com a sua idade; mostrava-se alegre, comunicativo, lúcido e com evolução psico-motora normal.

\section{COMENTARIOS}

Além de relatar alguns dos efeitos colaterais que podem surgir no tratamento com antiepiléticos, a casuística apresentada procurou demonstrar que esses inconvenientes podem ser bastante sérios, trazendo graves prejuizos ao paciente se não detectados a tempo.

Os casos relatados indicaram os seguintes efeitos colaterais das drogas antiepiléticas: distúrbios do humor (irritabilidade, depressão), da conduta (agressividade, impulsividade, tentativa de suicidio, atos obsessivos-compulsivos), do ritmo (lentificação) e do conteúdo do pensamento (auto-referência), do julgamento (estranheza em relação a si próprio e ao mundo circundante), da memória (hipomnésia de evocação e de fixação), da atenção (redução, dispersão), da vigilia (torpor), do sono (sonolência), da sexualidade (exarcebação), do rendimento intelectual (dificuldade de compreensão e de raciocínio abstrato), do pragmatismo (redução ou abolição), além de sintomas físicos como erupção cutânea alérgica (de tipo morbiliforme), cefaléia, náuseas, gastrite aguda com vômitos rebeldes aos anti-eméticos, hipertrofia gengival, desencadeamento ou exacerbação de crises convulsivas e de mioclonias, tremores, diplopia.

Também foi demonstrado que os sinais de intolerância podem surgir em conseqüência de diferentes fatores: sensibilidade individual (independente de dose e duração do tratamento), excesso de dose, tempo de uso do medicamento, combinação inadequada de drogas. 
A casuistica permite afirmar que sendo a intolerância aos medicamentos, em cada paciente, variável e imprevisível, é contraindicado o uso inicial de associação de antiepiléticos, hábito infelizmente bastante freqüente no nosso meio. Sendo impossivel descobrir, na associação, qual dos medicamentos é prejudicial, corre-se o risco de retirar o que está sendo benéfico, prejudicando ainda mais o paciente. Livingston ${ }^{3}$ enfatiza a necessidade de iniciar o tratamento com um único tipo de droga, escolhendo, como primeira, a que teoricamente mais se indica para o sintoma visado; se o remédio é parcialmente eficaz, a dose deve ser aumentada ou se introduz um novo medicamento; se é inefivaz, não há justificativa para que seja mantida. Marchand \& Ajuriaguerra ${ }^{4}$ aconselham a prescrição de fenobarbital sempre isolado, quando é o primeiro medicamento escolhido. Em nossa experiência, a prescrição isolada do antiepilético de primeira escolha, além de permitir uma apreciação mais justa de seu efeito, possibilita também a avaliação de cada nova droga introduzida, se uma associação se revelar necessária.

Alguns autores consideram a irritabilidade e os distúrbios de conduta, que surgem em muitos casos durante o tratamento antiepilético, uma decorrência inevitável, e preconizam a associação de sedativos para controle desses sintomas. Baseados nos casos descritos e em muitos outros que temos tratado, acreditamos que tais distúrbios indicam, freqüentemente, intolerância a uma droga ou excesso de dosagem; são necessárias, às vezes, várias tentativas terapêuticas para se obter o máximo de efeito com o mínimo de remédios, mas chega-se quase sempre a um esquema que dispensa a associação com neuroléticos, tranqüilizantes ou ansiolíticos. Essa conduta torna o tratamento menos oneroso e evita a sobrecarga de remédios que deve ser evitada em tratamentos prolongados.

Um outro ponto de discussão que a casuística suscita é o da necessidade ou não de haver um controle absoluto das crises epiléticas. Em nosso Serviço temos atendido com freqüência bastante grande, crianças e adolescentes epiléticos que passaram a manifestar distúrbios psíquicos graves após a instituição de tratamento anticomicial; preocupados em evitar que as crises epiléticas se repetissem seus médicos prescreviam medicamentos visando controlá-las, colocando em segundo plano as conseqüências da terapêutica sobre a atividade mental e a conduta. Em muitos desses casos temos conseguido, com a modificação do esquema terapêutico, controlar as crises e manter o paciente psiquicamente bem, como exemplifica o caso 5 . Outras vezes, porém, não se consegue obter o resultado ideal, como aconteceu no caso 6 ; diante da impossibilidade de controlar as crises mantendo o paciente psiquicamente bem, preferimos optar pela fórmula terapêutica que permitia uma conduta e um desenvolvimento psíquico normais, ainda que se manifestassem crises epiléticas ocasionais. Não se deve esquecer que homens como Moisés ${ }^{2}$, Buda 2, São Paulo Apóstolo ${ }^{2}$, Júlio César ${ }^{2}$, Sócrates ${ }^{2}$, Napoleão Bonaparte ${ }^{2}$ e Dostoiewski ${ }^{2}$ são, entre tantos outros, exemplos de figuras exponenciais na história da humanidade, que tiveram crises epiléticas ao longo de suas vidas.

O caso 4 é uma eloqüente demonstração do prejuízo das superdosagens e das combinações inadequadas de drogas. Desde os 2 anos de idade o pa- 
ciente vinha sendo tratado com doses altas de antiepiléticos e psicotrópicos e seu desenvolvimento mental, adequado até os 2 anos, mostrou-se nitidamente rebaixado depois que teve a primeira convulsão e iniciou tratamento. Aos 15 anos tinha atenção extremamente dispersiva, memória de fixação quase nula e freqüentes episódios caracterizados por graves distúrbios de características psicóticas. Suas crises foram controladas e sua capacidade de aprendizado melhorou com a menor dose de antiepilético que havia tomado até então, ou seja, com $50 \mathrm{mg}$ de fenobarbital. As altas doses de medicamentos com que fora tratado, dos 2 aos 15 anos, não conseguiram controlar totalmente sua sintomatologia e o mantinham com periodos alternados de embotamento e excitação. E justo admitir, diante desses fatos, que seu desenvolv:mento psico-motor e a adaptação à exigências de sua vida poderiam ter sido melhores se desde o inicio tivesse sido convenientemente tratado.

Acreditamos que ocorrências como essa expliquem o preconceito tão generalizado, não só entre leigos mas também na classe médica, de que o tratamento antiepilético produz rebaixamento mental. Em nossa experiência, evitando-se as drogas de efeito contraproducente e as doses excessivas, a produtividade intelectual do paciente não se prejudica e, ao contrário, melhora quase sempre.

\section{CONCLUSOES}

Exemplificando alguns tipos de efeitos colaterais que podem surgir na terapêutica antiepilética, a casuística apresentada procurou demonstrar que esses inconvenientes podem ser graves, principalmente se o medicamento não for logo suspenso ou a dose não for reduzida, conforme a indicação no caso. Demonstrou-se neste trabalho que esse tratamento pode provocar distúrbios do humor, da conduta, do pensamento, da memória, da atenção, da sexualidade, do julgamento, da vigilia, da produtividade intelectual, como também diplopia, cefaléia, tontura, gastrite e outros distúrbios físicos.

Ficou evidenciado que os sinais de intolerância podem depender de sensibilidade individual (ocorrendo com doses pequenas), como também de excesso de dose ou de tempo prolongado de uso. Foi demonstrado, em todos os casos, que o manejo cuidadoso e adequado de medicamentos substitutos, exclusivamente antiepiléticos, pode evitar esses efeitos e beneficiar plenamente o paciente, sem prejuízo do controle dos sintomas comiciais.

Devido ao pequeno número de medicamentos antiepiléticos em uso, ao fato de que nenhum deles é eficaz em todos os casos e que qualquer deles pode provocar efeitos colaterais, consideramos a epilepsia uma doença bastante difícil de ser tratada e baseados na experiência de atendimento destes e de muitos outros casos semelhantes, propomos algumas normas que ajudam o especialista a detectar e evitar esses efeitos eventuais o mais precocemente possivel, como sejam: 1 - iniciar o tratamento com um tipo de medicamento isolado e, como primeira escolha, empregar aquele que habitualmente se revela mais eficaz para a sintomatologia visada; 2 - se necessário, associar 
uma ou mais drogas, porém incluí-las progressivamente no esquema terapêutico, de forma a poder avaliar isoladamente seu efeito; 3 - excluir do tratamento as drogas que se revelarem ineficazes ou que provocarem efeitos colaterais indesejáveis; 4 - prescrever, no início, a menor dose de medicamento considerada eficaz para o caso, aumentando-a progressivamente, se necessário. Lembrar que quando predominam, no paciente, sintomas psíquicos, a dose terapêutica ideal costuma ser sensivelmente menor do que a necessária para controlar crises convulsivas freqüentes; 5 - se o paciente, submetido a tratamento antiepilético, apresentar algum sintoma psíquico ou somático que não seja claramente relacionado a uma doença simultânea, pensar na possibilidade de que se trate de um efeito colateral da terapêutica em uso, ainda que esse efeito não tenha sido mencionado na literatura médica; as investigações nesse terreno não estão esgotadas e são grandes as variações de respostas individuais; 6 - lembrar sempre que tratar epilepsia não é apenas controlar as crises, pois o paciente deve ser observado e tratado como um todo, sendo inaceitável que uma terapêutica antiepilética seja considerada bem sucedida quando o paciente deixa de ter crises porém paga o pesado tributo de ter outros órgãos ou funções afetadas pelos remédios ou sua atividade psíquica comprometida.

Embora o tratamento ideal deva levar ao controle total das manifestações ictais, consideramos menos prejudicial, ao paciente, ter crises ocasionais e ser capaz de uma atividade diária (pragmática e mental) satisfatória, do que ficar livre daquelas manifestações porém dopado pelos remédios, mentalmente rebaixado ou incapaz de atuar normalmente.

\section{RESUMO}

Relatando 6 casos de pacientes que apresentaram numerosos sintomas da esfera somática e fsíquica em conseqüência de tratamento feito com diferentes drogas antiepiléticas, os autores procuraram demonstrar que o remanejamento cuidadoso da terapêutica pode evitar esses inconvenientes sem prejuízo do controle dos sintomas comiciais. Os autores acentuam a necessidade dos médicos estarem atentos para a eventualidade de surgirem efeitos colaterais durante o tratamento antiepilético e, baseados em sua experiência, sugerem algumas normas de conduta para detectar precoecmente e evitar esses inconvenientes.

\section{SUMMARY}

Side effects and oversight in the antiepileptic treatment

Reporting 6 cases of patients who presented many psychiatric and somatic symptoms consequently to different antiepilectic treatments, the authors demonstrate that the careful changing of the therapeutic avoided these inconvenients, without jeopardizing the control of the epileptic seizures. The 
necessity for the specialists to be attentive to these side effects is emphasized. Based on their own experience the authors suggest a few rules to prevent and correct these inconvenients.

\section{REFERENCIAS}

1. BAPTISTETE, E. - Medo Patológico Não-Ictal: Manirestação Clínica da Epilepsia. Tese de Doutoramento apresentada na Clinica Psiquiátrica da FMUSP, São Paulo, 1969.

2. BRYANT, J. E. - Genius and Epilepsy. Ye Old Depot Press, Concord, 1953.

3. LIVINGSTON, S. - Diagnostico y Tratamiento de los Trastornos Convulsivos en la Infancia. Versão castelhana. Ed. La Medica, Rosario, 1956.

4. MARCHAND, L. \& AJURIAGUERRA, J. - Epilepsies. Desclée de Brower et Cie., Paris, 1948.

5. RIBAS, J. C.; BAPTISTETE, E.; FONSECA, C. A.: TiBA, I. \& COUTINHO FILHO, H. S. - Distúrbios de (onduta com predominio de agressividade, irritabilidade, impulsividade e instabilidade. Arq. Neuro-Psiquiat. (São Paulo) 32:187, 1974.

Serviço de Psiquiatria Infantil - Faculdade de Medicina - Caixa Postal 8091 - 01000 Süo Paulo, SP - Brasil. 